von den Innenzellen differenzierte Wandschicht. Diese Wandschicht ist für die Antheridien exogener Entstehung nöthig, für die endogener Entstehung, wie dies schon Waldner hervorgehoben, nicht ganz verständlich. Waldner gelangt zu folgender Annahme: "Die Differenzierung einer so vollkommen individualisierten Wandschicht bei den Antheridien von Anthoceros und in gewissem Sinne auch bei den Archegonien, und der Umstand, dass die Bildung dieser Hüllschicht vollkommen der der übrigen Lebermoose gleicht, lässt die Annahme als wahrscheinlich erscheinen, dass die Versenkung der Archegonien und die endogene Entstehung der Antheridien a bgeleit ete Vorgänge sind, dass also die hypothetischen Vorfahren unserer Anthoceroteen ihre Geschlechtsorgane aus oberflächlich gelegenen Zellen angelegt und dieselben ursprünglich über der Thallus-Oberfläche ausgebildet haben und dass somit die Ausbildung der Wandschicht an den Geschlechtsorganen unserer Anthoceroteen durch Vererbung zu erklären sei“.

Diese Auffassung erscheint nun gestützt durch das Auftreten von exogen entstandenen Antheridien. Vielleicht haben jene kümmerlichen Anthoceros-Pfänzchen die gegebenen Verhältnisse so am besten ausgenützt, vielleicht kommt als unwillkürlicher Rückschlag diese Entwicklung öfter vor ohne Beziehung zu äusseren Einflüssen; dies zu unterscheiden bedürfte es eines reichlicheren Untersuchungsmateriales, als es mir zur Verfügung stand.

Jedenfalls ist dieser offenbare Rückschlag, den wir als normalen Vorgang bei den anderen Lebermoosen kennen, nicht ungeeignet, einige Aufklärung zu gewähren über die Gruppe der Anthoceroteen, die einen einerseits so stark reduzierten, andererseits weit entwickelten Organismus darbieten.

Die Cultur, welche mir das Untersuchungsmaterial lieferte, ging bald zu Grunde. Einige Pfänzchen - es waren solche, die noch keine Antheridien angelegt hatten - konnten erhalten werden. Sie sind nun viel grösser als jene untersuchten, sind flächig ausgebreitet, dem Substrat angeschmiegt und zeigen keinerlei Anlage von Geschlechtsorganen.

\title{
Viola suavis M. B. in Ungarn.
}

Vor Kurzem sandte mir Herr Julius Gáyer in Kis-Czell eine Collection Veilchen aus der Gegend von Szombathek (Eisenburger Comitat). Bemerkenswert ist, dass sich darunter als Novität für die Flora Ungarns die echte $V$. suavis M. B. fand. Sie kommt vor in der schattigen Tiefe des Nadelwaldes (Pinus silvestris, Larix, Abies excelsa) bei Seé auf Sandboden (leg. J. Gáyer am 29. April 1900). Auch fand sie derselbe zwischen Seé und Olad (19. April 1900) und am Seéer Friedhof zwischen Gebüsch (17. März 1900). J. Gáyer bemerkt: „Die Blumen sind $2 \cdot 5$ bis $3 \mathrm{~cm}$ gross, ja auch etwas grösser. Kerner unterscheidet die V. suavis M. B. 
durch die doppelt grösseren Kronblätter von der V. sepincola Jord. $(=V$. austriaca Kerner); vergl. Oest. bot. Zeitschr. 1874, p. 168. Die Blüten sind hier viel grösser als die der gewöhnlichen $V$. sepincola. In der Farbe ist kein Unterschied."

Die vorliegenden Exemplare sind völlig identisch mit Pflanzen aus dem südlichen Russland und entsprechen vollständig den Diagnosen in M. B. Taur. Cauc. III, p. 164, in Koch-Wohlfahrt, Syn. ed. III, p. 172, in Koch, Syn. ed. III (1857), p. 73, in Hallier, Fl. v. Deutschl. 1272 und in Sturm's Flora. Ich verzichte darum auf eine Wiedergabe der.Beschreibung und weise auf die genannten Floren hin.

Im Nadelwald fand sich auch Viola hirta L. X suavis I. B. hybr. nov. vor. Sie unterscheidet sich von $V$. suavis durch stärkere Behaarung der Blätter, durch deren geringere Breite und tiefere Basilarbucht. Im Gegensatz zu $V$. hirta hat sie weniger behaarte, nach der Spitze zu verkahlende, breiteiförmige Blätter mit zum Theil flacherer Basilarbucht. Die Nebenblätter sind lang, deutlich gefranst; die Fransen tragen eine Drüse. Ausläufer sind nicht vorhanden; jedoch dürften sich solche entwickeln. Die Blätenfarbe ist an den vorliegenden Exemplaren gänzlich verblasst, sie wäre der Blütenfärbung der Eltern gemäss hellblau mit deutlich weissem Schlunde.

Ich benenne diese Hybride nach dem Finder Viola Gayeri.

Hedersleben, Bez. Magdeburg, den 4. Angust 1903. W. Becker.

Kleinere Arbeiten des pflanzenphysiologischen Institutes der Wiener Universität. XXXVII.

\section{Ueber Assimilationserscheinungen der Blätter anisophyller Sprosse.}

\section{Von Josef Schiller.}

Im ptlanzenphysiologischen Institute der Wiener Universität mit einer grösseren Untersuchung über Assimilationserscheinungen beschäftigt, schien es mir höchst interessant zu sein, auch die Blätter anisophyller Sprosse in Bezug auf ibre Assimilationsgrösse in den Kreis meiner Beobachtungen einzubeziehen, welche ich hier in Kürze vorführen will.

Diese Beobachtungen bezogen sich auf nachfolgende Arten:

Acer tataricum, Ac. monspessulanum, Ac. Pseudoplatanus, Ac. platanoides, Ac. obtusatum, Ac. campestre, Ac. dasycarpum, Ac. Negundo, Ac. californicum, Ac. macrophyllum.

Aesculus Hippocastanum. Macrothyrsus parviflora (Aesculus parviflora Walt). 